\title{
Electoral Rules, Strategic Entry and Polarization*
}

\author{
Damien Bol $^{\dagger} \quad$ Konstantinos Matakos ${ }^{\ddagger}$ Orestis Troumpounis ${ }^{\S}$ \\ Dimitrios Xefteris
}

August 22, 2019

\begin{abstract}
How does electoral rule disproportionality affect the structure of the party system (i.e. the number and the policy platforms of the competing parties)? By studying a model where both party entry and platform choice are endogenous we are able to provide a unified theory: An increasing electoral rule disproportionality exhibits: a) a first-order negative effect on platform polarization, b) a second-order negative effect on the number of parties (as polarization decreases, centrist parties are squeezed between other contenders and prefer not to enter), and c) an additional third-order negative effect on polarization via the reduction of the number of parties. We then conduct a laboratory experiment and strongly confirm the theoretical predictions of the model.
\end{abstract}

Keywords: electoral systems; proportional representation; disproportionality; strategic entry; polarization; laboratory experiment

JEL codes: D72, C91

* The paper benefited significantly from the constructive comments of two anonymous referees and the co-editor, Erik Snowberg. We are also grateful to Laurent Bouton, Thomas Bräuninger, Wioletta Dziuda, Konstantinos Georgalos, Emma Manifold, Konstantinos Protopappas, and Stephane Wolton. For valuable feedback we thank participants in the following events: EPSA, ECPR, and MPSA conferences, Barcelona GSE Summer Forum, KCL workshop on game theory, Mannheim workshop on spatial models of party competition, PSE Brownbag Seminar of the Behaviour Group.

${ }^{\dagger}$ Department of Political Economy, King's College London, Bush House NE, 30 Aldwych Street, London, WC2B 4BG, UK; e-mail: damien.bol@kcl.ac.uk

${ }^{\ddagger}$ Department of Political Economy, King’s College London, Bush House NE, 30 Aldwych Street, London, WC2B 4BG, UK; e-mail: konstantinos.matakos@kcl.ac.uk

$\S$ University of Padova, via Del Santo 33, 35137, Italy \& University of Lancaster, The Management School, UK, e-mail: orestis.troumpounis@unipd.it

『Department of Economics, University of Cyprus, PO Box 20537, 1678 Nicosia, Cyprus, e-mail: xefteris.dimitrios@ucy.ac.cy 


\section{Introduction}

The rules of the electoral game matter a great deal. Electoral institutions have been shown to affect a constellation of economic and political outcomes such as, to name a few: redistribution, public spending and public good provision (e.g. Lizzeri and Persico 2001; Milesi-Ferretti et al. 2002; Persson et al. 2003, 2007), turnout (e.g. Blais and Dobrzynska 1998; Herrera et al. 2016), and campaign spending (Iaryczower and Mattozzi 2013). Importantly, since Duverger (1954) we know that electoral rule disproportionality (understood broadly as the size of the electoral advantage assigned to the winner of the election) affects the structure of the party system (i.e. the number and policy platforms of the competing parties). Indeed, it is a stylized fact that the number of competing parties is higher in proportional representation (henceforth PR) systems compared to more disproportional ones, and that proportional systems provide parties with stronger centrifugal incentives than disproportional ones such as the plurality rule or first-past-the-post (e.g. Cox 1990; Calvo and Hellwig 2011; Matakos et al. 2016). ${ }^{1}$

Yet, despite electoral institutions altering parties' incentives to enter the electoral race but also to propose moderate or extreme platforms, our understanding -both theoretically and empirically- about the exact mechanisms via which electoral rules operate is rather incomplete. That is, are the effects of electoral rules on party entry and platform choice independent, or are they intertwined, thus making it more difficult to establish clear causal links? For instance, could it be that electoral rule disproportionality has direct effects only on the number of parties that decide to enter, and that platform decisions are only indirectly affected by the number of competing parties? Is it likely that the opposite holds (i.e. that electoral rules affect only platform selection, and this indirectly determines entry decisions)? Or, even, could it be that electoral rules affect both entry and platform selection incentives in a more convoluted manner?

The current literature has not revealed the exact mechanism via which electoral rules jointly affect entry and platform decisions. Typically, existing approaches instead analyze the effects of the electoral rule on electoral competition by focusing either on entry decisions, or on platform selection independently. ${ }^{2}$ The literature that focuses on entry decisions often builds on the citizen-candidate approach (a là Osborne and Slivinski 1996; Besley and Coate 1997). Yet candidates' platforms are exogenously fixed -once they

\footnotetext{
${ }^{1}$ For a more extensive review on the literature regarding the effects of electoral rules on various outcomes one is referred to Lijphart (1994), Taagepera and Shugart (1989), Persson and Tabellini (2002, 2005), and Grofman (2008).

${ }^{2}$ To be fair, there are few papers that consider both endogenous entry and platform decisions by all parties (e.g. Feddersen et al. (1990), Osborne (1993), Xefteris (2016)), but different to our work those a) focus entirely on variations of simple plurality rule and/or runoff systems, and b) even in the context of the plurality rule do not consider that candidates have substantial policy concerns.
} 
enter the election, they do so in a predetermined position- and, hence, cannot answer the posited questions. ${ }^{3}$ Similarly, the literature which assumes an exogenous number of parties and endogenous platform selection cannot provide the necessary answers since it effectively shuts down the entry channel. ${ }^{4}$ In other words, there is no formal analysis examining the simultaneous effects of electoral rule disproportionality on party entry and platform choice and, at the same time: a) focuses on parties' strategic decisions, ${ }^{5}$ b) considers endogenous entry, and c) allows for the choice of platform to be endogenously determined. Indeed, the last two points are essential if one is to account for a potentially intertwined relationship between platform and entry decisions. In this paper we undertake the task of formulating such an argument and fill the described gap in the literature.

We consider a formal model in which parties compete under a continuum of alternative electoral rules that differ only in terms of disproportionality, and where both entry and platform decisions are endogenous. The parties are mainly policy motivated, in the sense that they want the implemented policy to be as close as possible to their ideal policies, but also care about their office rents reflected in their parliamentary power. In specific, a party in our framework is willing to participate in the election if by doing so it can influence the implemented policy to its benefit, or if it can secure substantial parliamentary power. If neither of these conditions are met, then it prefers to save the cost of entering the election. Under these assumptions, we show that both the number of parties that decide to enter and platform polarization (throughout the paper defined as the distance between the two most distant platforms) are decreasing in electoral rule disproportionality. That is, our theoretical results are in line with existing stylized facts confirming the original Duvergerian predictions and linking PR systems with higher polarization than disproportional ones.

But more importantly, we identify a three-step mechanism that may lie behind these stylized facts, and which uncovers that electoral rules do not exhibit only direct effects on entry and polarization incentives. A more intricate logic seems to be in operation. As more disproportional rules generate centripetal forces (see e.g. Cox 1990) and ex-

\footnotetext{
${ }^{3}$ The original citizen candidate models focus on plurality rule and have been extended over several alternative rules and dimensions. Among other, see for example Hamlin and Hjortlund (2000); Morelli (2004); Levy (2004); Iaryczower and Mattozzi (2013); Dellis (2013); Dellis and Oak (2016). For a review of models where candidacy is endogenous the reader is referred to Bol et al. (2016).

${ }^{4}$ This literature is really vast, and fully presenting it is beyond the scope of this paper. A recent discussion of several relevant references may be found in Matakos et al. (2016).

${ }^{5} \mathrm{~A}$ large body in the formal literature has focused, instead, on voters' strategic decisions and detected the coordinating consequences that electoral rules have on voters' behavior. In those papers, the sole focus is on voters: party platforms are exogenous and no entry decisions are made (see e.g. Austen-Smith and Banks 1988; Fey 1997; Gerber and Ortuño-Ortín 1998; Baron and Diermeier 2001; De Sinopoli and Iannantuoni 2007; Baron et al. 2012; Troumpounis and Xefteris 2016).
} 
treme parties move towards the center (first-order effect), centrist parties are squeezed by competition and might eventually drop out (second-order effect). Thus, the electoral rule influence on entry decisions operates mainly via polarization. Interestingly, this generates an additional feedback effect: as the number of parties decreases, polarization becomes even lower in reaction to the smaller number of competing parties (third-order effect). ${ }^{6}$ That is, an increasing electoral rule disproportionality exhibits both a direct (first-order effect) and an indirect (third-order effect) negative force on polarization, and a negative force on the number of competing parties (second-order effect).

This bi-directional relationship between platform positions (polarization) and the number of competing parties (entry decision) implies that, despite widespread empirical support for the aggregate prediction, conclusive causal evidence is still wanting and, arguably, hard to obtain by the means of real elections' results. For this reason we turn to the laboratory and design an experiment in line with the main assumptions of our theoretical model. In this way we can test not only for the aggregate effect of electoral rule disproportionality on the number and the platforms of parties, but also for the relevance of the described two-way relationship between platform and entry choices and the resulting feedback effect.

In our experiment we limit attention to the two most asymmetric rules in terms of disproportionality (the plurality rule and the PR) and we find strong support for our theoretical predictions. In aggregate terms, the number of parties and polarization are found to be significantly higher under PR than under plurality; however, we do find excessive entry under PR compared to the theoretical benchmark. Moreover, the described three-step mechanism seems to be in full operation: a) for a fixed number of parties, polarization decreases when we move from a PR rule to plurality (first-order effect), b) entry (by the centrist party) is smaller under plurality compared to a PR rule in anticipation of lower polarization (second-order effect), and c) for a given electoral rule, polarization is decreasing in the number of parties (third-order effect).

There is a long literature in which researchers have tested in the laboratory the effect of electoral rules on various aspects of electoral competition. ${ }^{7}$ There are two sets of experimental studies that more specifically study the strategic entry of candidates in an electoral context: those that follow variations of the classic Hotelling-Downs model, and which typically assume an exogenous number of candidates and pure office motives (among a large literature see for e.g., Huck et al. 2002; Aragones and Palfrey 2004; Bol

\footnotetext{
${ }^{6}$ Palfrey (1984) and Cox (1990) are representative studies showing that polarization is increasing in the size of realized or anticipated entry.

${ }^{7}$ Comparative experimental analysis across different electoral rules has recently also focused on other relevant issues such as information aggregation (Battaglini et al. 2010; Bouton et al. 2016; Herrera et al. 2019a,b), turnout (Herrera et al. 2014) and vote buying (Casella et al. 2012; Tsakas et al. 2018). For a broader review of lab experiments in political economy, see e.g. Palfrey (2009).
} 
et al. 2018), and those that follow the citizen-candidate model (Cadigan 2005; Elbittar and Gomberg 2009; Kamm 2017; Grosser and Palfrey 2019). ${ }^{8}$ The latter are closer to ours because they study the choice of candidates to enter or not, and assume that these candidates have policy motives in the sense that their payoff is, at least in part, a function of the distance between their ideal policy position and the policy position ultimately implemented after the election. However, these studies differ from ours in several important aspects. First, in Cadigan (2005), Elbittar and Gomberg (2009), Kamm (2017), and Grosser and Palfrey (2019), the candidates only choose whether to enter or not. They cannot choose their policy platform strategically, as they can only compete under their ideal policy position. Second, our experiment tests the model predictions for two electoral rules: plurality and proportional representation. Only Kamm (2017) compares these two electoral rules and also finds that entry is larger under proportional representation, while others restrict themselves to plurality rule (Cadigan 2005; Grosser and Palfrey 2019), sometimes in combination with majority runoff (Elbittar and Gomberg 2009). Finally, unlike Grosser and Palfrey (2019), but similar to other studies, the candidates in our experiment have complete information about the ideal policy positions of other participants, and so do voters. By contrast, Grosser and Palfrey (2019) study an environment with incomplete information, in which voters can only infer candidates' position from equilibrium outcomes. Our experiment is thus unique, as it allows the candidates to enter or not the election, and to compete under the policy platform of their choice, which might or might not be the same than their ideal position.

Overall, our work makes a dual contribution. On the theory side, existing approaches that allow for both endogenous entry and platform selection -even solely in the context of plurality rule- do not consider that candidates have substantial policy concerns, and hence cannot pin down the identified relationship between entry and polarization (see Bol et al. 2016). Moreover, this is the first study that formally documents the simultaneous existence of three intertwined channels through which electoral rules affect parties' entry and platform decisions. On the experimental side, our study is the first to propose a comprehensive test of a political competition model under plurality and proportional rules, in which both the platform choices and entry decisions are made endogenously by the participants. As a result, our research design allows us to account for the twoway relationship between polarization and candidate entry that our theory predicts and

\footnotetext{
${ }^{8}$ Tsakas and Xefteris (2018) is placed somewhere in between these groups of papers since it tests in the laboratory a generalization of the Palfrey (1984) entry model. That is, while entry concerns are important in determining the candidates' platform choices, the choice of running (or not) is still not a strategic choice: the two mainstream candidates necessarily enter, and a third candidate -played by the computer- enters with a given probability. In our study, both choices (entering or not, and in which position) are endogenous.
} 
fully characterize the effects of the electoral rule (dis)proportionality on the party-system structure.

In what follows, we first present our theoretical arguments (Section 2), then we describe our experimental design and results (Section 3), and, finally, we conclude (Section 4). In the Appendix we prove our main theoretical result and provide additional empirical analysis.

\section{Theory}

\section{The Model}

In order to incorporate parties' entry decision we consider the following "standard" two stage entry game: In the first stage, parties decide whether to enter the (costly) electoral race or not. In the second stage, each competing party observes which other parties entered the race and strategically selects its political platform. Parties' strategic behavior then determines the electoral outcome and implemented policy (as later detailed), and hence the subsequently realized payoffs. We focus on subgame perfect equilibrium (SPE) in pure strategies where the distribution of policy proposals in the second stage is symmetric around the center of the policy space.

The policy space is assumed to be continuous, unidimensional, and represented by the interval $\Pi=[0,1]$. There are three parties $j=L, C, R$. The leftist party $L$ has ideal policy $\pi_{L}=0$, the centrist party $C$ has ideal policy $\pi_{C}=0.5$, and the rightist party $R$ has ideal policy $\pi_{R}=1$. Each party $j$ has to make an entry choice $e_{j}=\{0,1\}$ where 1 stands for "entry" and 0 stands for "no entry", and, a platform choice $p_{j} \in \Pi$.

Parties have mainly policy concerns and have only as a secondary priority office motives. Formally, parties have lexicographic preferences with their first priority being to minimize the distance between the implemented policy $\hat{p}$ and their ideal point. ${ }^{9}$ That is, they aim at maximizing $U_{j}(\hat{p})=-\left|\hat{p}-\pi_{j}\right|$, where $\hat{p}$ is the implemented policy. If multiple strategies offer them the same maximal value of $U_{j}(\hat{p})$ then they refine their choice by their second priority. Their second priority is related to their office motives and they aim at maximizing $\psi_{j}=S_{j}-c$ where $S_{j}$ denotes party's $j$ seat share and $c=\hat{c}>0$ is the cost of entering the race with $c=0$ if they do not enter. Finally, when parties are indifferent between announcing two distinct platforms, after taking into account both

\footnotetext{
${ }^{9}$ Let us stress that lexicographic preferences do not determine the qualitative characteristics of our results. We could have instead assumed that parties have mixed motives, with sufficiently low weight on the office concerns dimension. Given the analytical complexities of such a framework we can only derive computational results for this smoother case that are available by the corresponding author upon request. Nevertheless, these computational results are in line with the formal results that we obtain in the lexicographic preferences setup presented here.
} 
priorities, then we assume that they prefer to announce the one that is closer to their ideal policy; and, also, when parties are indifferent between entering or not, after taking into account both priorities, then we assume that they enter. ${ }^{10}$ In order to guarantee that the entry cost is not the determinant of the qualitative features of the equilibrium we assume that $\hat{c}<0.25$.

\section{Voting, electoral outcome and implemented policy}

We assume that there is a continuum of voters, uniformly distributed on the policy space. Given parties' entry decisions and their corresponding platform proposals, voters vote in a sincere manner the party that proposed the platform closest to their ideal policy. If a voter is indifferent between two or three platforms then she randomizes her vote.

If two parties enter and propose distinct platforms, we are in a standard two-party competition model where voters on the left of the indifferent voter vote for the party proposing the leftist platform and voters on the right of the indifferent voter vote for the party proposing the rightist platform. If all three parties enter the race and propose distinct platforms, then there exist two indifferent voters and three "bands" of voters supporting each of the three parties. If two or three parties happen to propose identical platforms then one just has to keep track of voters randomizing their vote. Obviously, if only one party enters then it obtains all votes.

If at least one party enters the election let $V_{j}\left(\left(e_{L}, p_{L}\right),\left(e_{C}, p_{C}\right),\left(e_{R}, p_{R}\right)\right)$ denote $j$ 's vote share in the election. We then follow (Theil 1969; Taagepera 1986), and given parties' vote shares $V_{j}$, each party is allocated the following seat share:

$$
S_{j}\left(\left(e_{L}, p_{L}\right),\left(e_{C}, p_{C}\right),\left(e_{R}, p_{R}\right) ; n\right)=\frac{V_{j}^{n}}{V_{L}^{n}+V_{C}^{n}+V_{R}^{n}}
$$

where $n \geqslant 1$ captures the electoral rule disproportionality. In general, for $n=1$ seat shares correspond to the exact vote shares and hence one refers to a pure proportional electoral system. As $n$ however increases, the winning party is favored disproportionately. This simplified manner of mapping electoral outcomes to parliamentary power has been recently used by Saporiti (2014); Matakos et al. (2016); Herrera et al. (2016) among others to map in a tractable manner the distortions generated by the electoral rule. Figure 1 summarizes the seat share allocation using this formula for different levels of disproportionality in two and three-party competition.

The implemented policy $\hat{p}$ instead is a function of parties' power in the parliament $S_{J}$ and parties' proposed platforms $\left(p_{L}, p_{C}, p_{R}\right)$. Formally, the implemented policy is given

\footnotetext{
${ }^{10}$ These last assumptions help us pin down a unique prediction in certain non-generic cases, and have no effect on the substantive part of our analysis.
} 


\section{Two-party competition:}
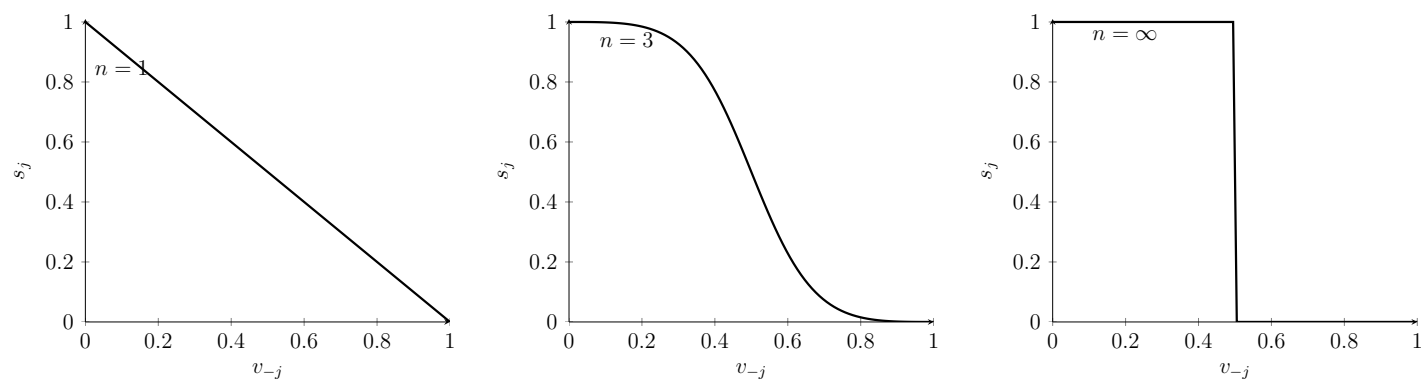

\section{Three-party competition:}
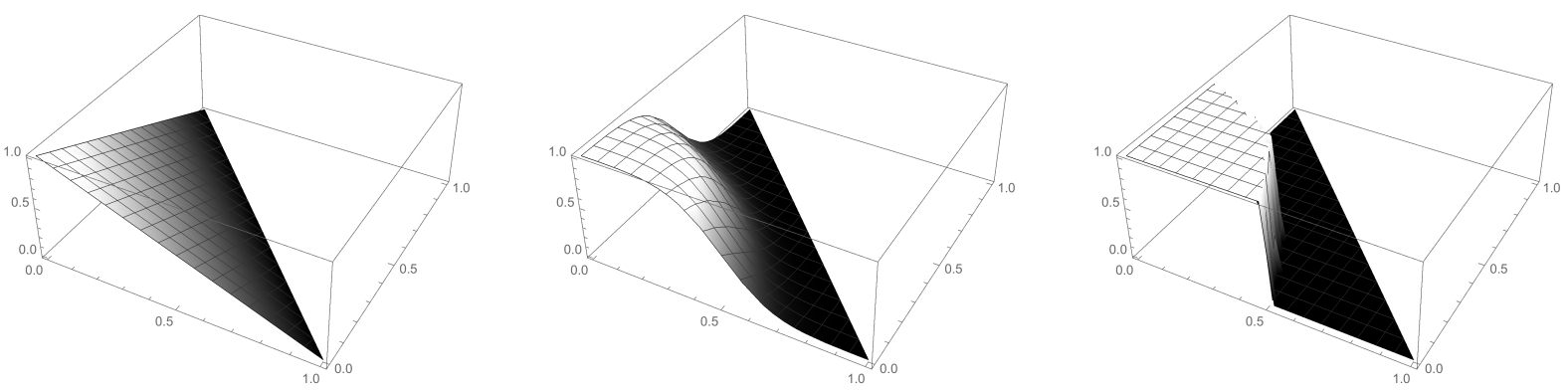

Figure 1: A party's seat share as a function of its competitor(s) vote share(s) following Theil's rule for two and three-party competition. The graphs on the left represent a pure PR system where $n=1$. The middle graphs a disproportional rule where $n=3$. The right graphs a "winner-take-all" plurality rule where $n \rightarrow \infty$. For $n>1$ the winner of the election is favored by the electoral rule, and this advantage is becoming bigger as $n$ increases.

by:

$$
\hat{p}\left(\left(e_{L}, p_{L}\right),\left(e_{C}, p_{C}\right),\left(e_{R}, p_{R}\right) ; n\right)=\sum_{j=L, C, R} S_{j}\left(\left(e_{L}, p_{L}\right),\left(e_{C}, p_{C}\right),\left(e_{R}, p_{R}\right) ; n\right) * p_{j}
$$

This function captures a consensual democracy (Lijphart 1984; Alesina and Rosenthal 1996), where the implemented policy reflects a post electoral compromise. Each party's weight in such compromise is determined by its parliamentary power. ${ }^{11}$ For simplicity we assume that if no party enters the election, a status quo policy $q \in[0,1]$ is implemented and that this status quo policy is known to all parties (this assumption can be relaxed).

\footnotetext{
${ }^{11}$ For compromise models under PR elections see Austen-Smith and Banks (1988); Ortuño-Ortín (1997); Gerber and Ortuño-Ortín (1998); Merrill and Adams (2007); Llavador (2006); De Sinopoli and Iannantuoni (2007, 2008); Matakos et al. (2016) among others.
} 


\section{Theoretical Results}

We can now state the main proposition regarding parties' equilibrium entry and platform choice decisions.

Proposition 1. There exists a unique equilibrium and a unique $\hat{n}>0$ such that: (i) for $n \leq \hat{n}$ all three parties enter and their platform choices are $\left(p_{L}^{* * *}, p_{C}^{* * *}, p_{R}^{* * *}\right)=\left(\frac{1}{2}-\right.$ $\frac{1}{n+1}, \frac{1}{2}, \frac{1}{2}+\frac{1}{n+1}$ ) (ii) for $n>\hat{n}$ only parties $L$ and $R$ enter and their platform choices are $\left(p_{L}^{* *}, p_{R}^{* *}\right)=\left(\frac{1}{2}-\frac{1}{2 n}, \frac{1}{2}+\frac{1}{2 n}\right)$.

\section{The proof of Proposition 1 can be found in the Appendix.}

The above result is illustrated in Figure 2a. For a given entry cost, if the electoral system is sufficiently proportional (low values of $n$ ) all three parties have incentives to pay the entry cost and compete in the election. In the case of three-party competition, the centrist party sticks to its ideal policy $\left(p_{C}^{* * *}=\frac{1}{2}\right)$ while the two other parties announce platforms that diverge symmetrically around that point. As the electoral system becomes more disproportional, the two extreme parties converge towards the center and suppress the seat share of the centrist party (first-order effect). From a point on (when $n>\hat{n}$ ), the seat share of the centrist party is suppressed sufficiently such that the centrist party is better off by not paying the entry cost (second-order effect). Notice that no matter whether two or three parties compete the implemented policy coincides with the ideal point of the centrist party. That means that the centrist party enters the election only to maximize its office benefits (its second priority). Hence for sufficiently disproportional electoral systems, only two parties remain active in the political arena. ${ }^{12}$

As we have shown, the electoral rule affects both the number of parties and polarization (polarization is defined throughout the paper as the distance between the two most extreme platforms). But note that its effect on polarization is actually twofold. Figure $2 \mathrm{~b}$ helps to illustrate this argument. First, note that for a given number of parties, there is a direct negative effect of the disproportionality of the electoral rule on polarization. As the rule becomes more disproportional, parties $L$ and $R$ tend to propose more centrist platforms. This direct effect highlights that for a given number of parties, more

\footnotetext{
${ }^{12}$ While we consider that the employed sequential timing -first entry then platform choice- is realistic and captures the dynamics of electoral competition in several contexts, it is obviously not the only relevant one. Hence, we should note that our results qualify to a simultaneous version of our model in which both entry and platform decisions take place simultaneously, with the following modification: while the sequential version that we study admits a unique equilibrium for (essentially) every level of disproportionality, the simultaneous version would admit two equilibria for intermediate disproportionality levels (one with two entrants and one with three). That is, the comparative results that we have identified would still hold but in an, arguably, coarser way: As disproportionality increases the number of entrants in equilibrium will decrease, but this now means that there are two disproportionality levels $n^{\prime}$ and $n^{\prime \prime}$ such that for $n<n^{\prime}$ we have three entrants, for $n$ in $\left[n^{\prime}, n^{\prime \prime}\right]$ we have either two or three entrants and for $n>n^{\prime \prime}$ we have two entrants. Similarly, polarization decreases with disproportionality.
} 


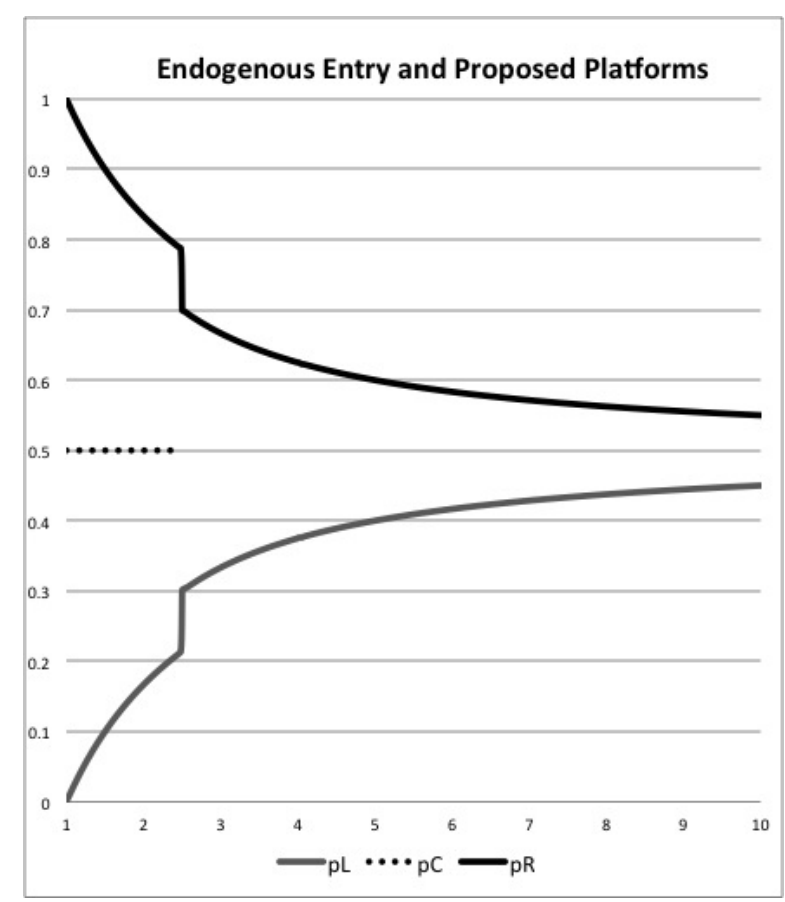

(a) Proposed platforms as a function of $n$ as characterized in Proposition 1 ( $c=0.22$ which implies that $\hat{n}=2.5)$.

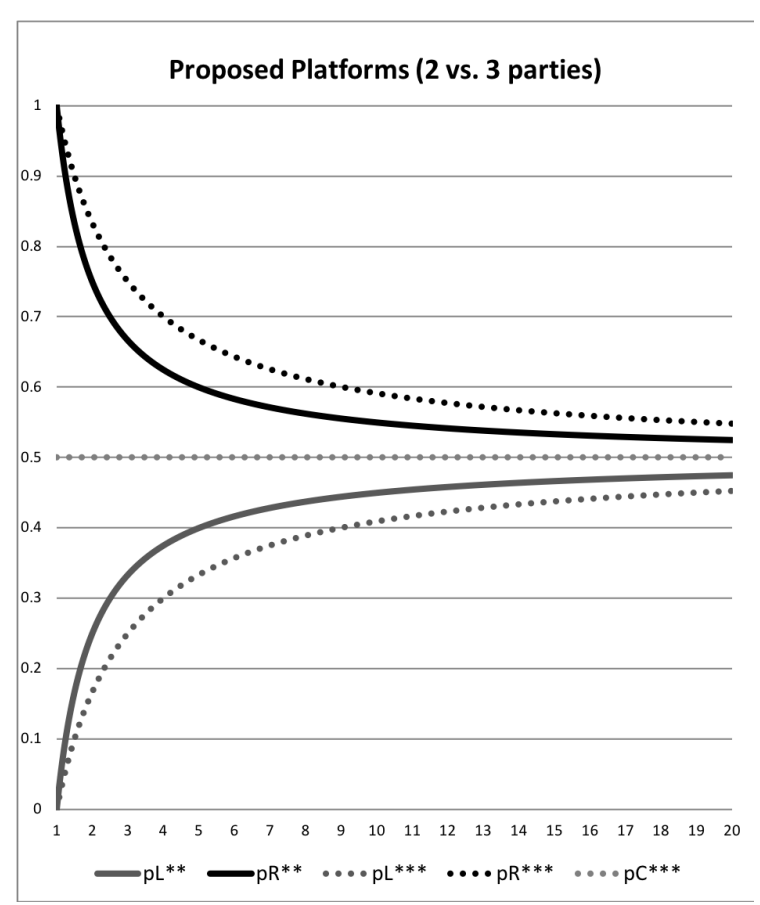

(b) Proposed platforms for a given number of parties as a function of $n$ (three parties with dotted lines, two parties with solid lines).

Figure 2: The effect of electoral disproportionality $n$ on the number of parties and polarization.

proportional electoral rules are associated with higher levels of polarization. Second, as the same graph highlights, the number of parties also affects polarization. That is, for a given level of disproportionality, polarization is higher in a three-party election than in a two-party election. Hence, for any rule, increasing entry from two to three parties, endogenously increases polarization. ${ }^{13}$ This is because when three parties compete, the presence of the centrist party makes the extreme parties less willing to converge towards the centre than in the two party case. But note that as we have shown in Proposition 1 and Figure 2a, the electoral rule affects the number of competing parties. Hence via the endogenous change in the number of parties, the electoral rule has also an additional indirect effect on polarization (third-order effect). ${ }^{14}$ The above effects of the electoral

\footnotetext{
${ }^{13}$ Similarly, in a variant of our model where platforms are fixed at $(1-x, 1 / 2, x)$ and only entry is endogenous, for any electoral rule disproportionality the number of entrants can be shown to increase in $x$.

${ }^{14}$ While an extension to an arbitrary number of parties is not tractable, it is noteworthy that the basic forces supporting our formal results do not seem to crucially depend on the exact number of players. In every strategy profile in which the candidates that decide to enter occupy distinct locations, the incentives of the two most extreme entrants to move towards the center become stronger as the rule rewards more intensely any increase in their vote shares. But also a potential move of the extremists towards the center will cause a loss of votes for their neighboring more moderate entrants, and thus exiting will become more attractive for them.
} 
disproportionality on the number of parties and polarization can be summarized in the following testable hypotheses:

Hypothesis 1 [first-order effect]: For a given number of parties the electoral rule disproportionality has a negative effect on polarization (Figure 2b).

Hypothesis 2 [second-order effect]: The electoral rule disproportionality has a negative effect on the number of parties due to the centrist party not entering the electoral competition (Figure 2a).

Hypothesis 3 [third-order effect]: For the same electoral rule disproportionality, a smaller number of parties leads, generically, to lower polarization (Figure 2b).

Whether these three channels operate simultaneously or not is unfortunately difficult to test in an empirical context. Therefore experimental investigation seems appropriate for this setting.

\section{The Experiment}

We conducted 14 experimental sessions between January 2018 and March 2019 at the LExEL Lab of the University of Lancaster with 190 unique subjects participating in the experiment. The pool of participants is composed of undergraduate and postgraduate university students from various degrees. Participants were recruited using standard procedures via ORSEE (Greiner 2015) and the experiment was executed on z-Tree (Fischbacher 2007).

Each session involved 10 or 15 participants (depending on the treatment) playing the role of candidates. In each session, subjects were matched in 5 groups (of 2 or 3 ). Each subject played for 25 times. Hence, in each session we collected $5 * 25=125$ observations at the "election" level. Depending on whether the treatment required two or three participants at each group, we collected 250 or 375 decisions at the "individual" level. We hence have data for a total of 1745 elections and 4735 individual decisions. ${ }^{15}$ Six treatments were designed to test the previously stated hypotheses and are summarized in Table 1.

Treatments T1 and T2 are our main treatments with endogenous entry across electoral rules, replicating closely the theoretical model previously presented. Treatments T3-T6 instead shut down the entry channel and focus on an exogenous number of parties. Since T3-T6 are simplified versions of T1 and T2, we first detail the experimental design of

\footnotetext{
${ }^{15}$ There was a technical problem in one of the experimental sessions conducting one of the three T2 treatments. We lost the data for the last period of the session, meaning 5 elections and 15 individualdecisions.
} 
Table 1: Experimental Treatments

\begin{tabular}{lllllll}
\hline Treatment & T1 & T2 & T3 & T4 & T5 & T6 \\
\hline Number of parties & Endogenous & Endogenous & 3 parties & 3 parties & 2 parties & 2 parties \\
Electoral rule & PR & Plurality & PR & Plurality & PR & Plurality \\
\hline Number of sessions & 3 & 3 & 2 & 2 & 2 & 2 \\
Number of elections & 375 & 370 & 250 & 250 & 250 & 250 \\
\hline
\end{tabular}

the "endogenous" T1-T2 treatments. We then present the necessary modifications to implement the "exogenous" T3-T6 treatments.

In each session implementing $\mathrm{T} 1$ or $\mathrm{T} 2$, there are 15 participants playing in 5 groups of 3. The groups are formed randomly, and groups play together for a series of 5 elections. Groups are randomly reshuffled at the end of each series of 5 elections for 5 times. That is, in each session, each participant makes 25 decisions (five series of five elections). ${ }^{16}$ In each group, participants are randomly assigned to an ideal policy on a discrete policy space from 0 to 10 that they maintain throughout the series of five elections. The randomization is made so that, in each group, there is one participant at position $0(\mathrm{P} 0)$, one at position 5 (P5), and one at position 10 (P10).

For each election, participants in the same group play the following two stage game: In the first stage, participants knowing their ideal policy, simultaneously decide whether to enter the election or not (at a cost). At the end of the first stage, participants that entered the election see on their screen the ideal policies of other entering participants within their group.

In the second stage, the participants who entered the election in the first stage propose a policy platform. They can propose any discrete point on the 0-10 scale. Then, 11 voters who are also located on the 0-10 scale, one at each discrete point, and who are played by the computer, vote. Their vote follows a simple rule: they vote for the platform that is the closest to them. In case they are equally close to two or three platforms, their vote is equally split between these platforms. Table 2 gives a representation of a typical situation of the experimental game where all three participants P0, P5 and P10 entered the election and proposed platforms 1,5 and 6 respectively. ${ }^{17}$

\footnotetext{
${ }^{16}$ Despite our theoretical prediction referring to a one-shot game and the implemented version in the lab being of repeated nature, there are several reasons that reassure us regarding the validity of the theoretical predictions. First, note that subjects are matched in the same group for only 5 rounds. Given the short span, it would be difficult for players to figure out and implement a coordination strategy that would prove mutually beneficial. Moreover, the equilibrium of the one-shot game performs rather well in utilitarian terms (i.e., in equilibrium the sum of individual utilities is either maximal, or very close to being so) making mutually beneficial deviations wanting. Perhaps more importantly, since the one-shot game admits a unique equilibrium, the corresponding repeated game should admit a unique subgame perfect equilibrium which follows the equilibrium strategy of the one-shot game in every period.

${ }^{17}$ Note that we did not present the game as a simulation of elections to participants. To facilitate the
} 
Table 2: Example of an experimental situation

\begin{tabular}{|c|c|c|c|c|c|c|c|c|c|c|c|c|}
\hline \multicolumn{3}{|l|}{ Proposals } & \multicolumn{4}{|l|}{$\mathrm{P} 0$} & \multicolumn{3}{|c|}{ P5 $\quad$ P10 } & \multirow[b]{2}{*}{8} & \multirow[b]{2}{*}{9} & \multirow[b]{2}{*}{10} \\
\hline Platform & & 0 & 1 & 2 & 3 & 4 & 5 & 6 & 7 & & & \\
\hline Voters & & V0 & V1 & $\mathrm{V} 2$ & V3 & V4 & V5 & V6 & V7 & V8 & V9 & V10 \\
\hline & Total & & & & & & & & & & & \\
\hline Votes for P0 & 3.5 & 1 & 1 & 1 & .5 & 0 & 0 & 0 & 0 & 0 & 0 & 0 \\
\hline Votes for P5 & 2.5 & 0 & 0 & 0 & .5 & 1 & 1 & 0 & 0 & 0 & 0 & 0 \\
\hline Votes for P10 & 5 & 0 & 0 & 0 & 0 & 0 & 0 & 1 & 1 & 1 & 1 & 1 \\
\hline
\end{tabular}

The treatment across $\mathrm{T} 1$ and $\mathrm{T} 2$ is the disproportionality of the electoral rule. T2 implements the plurality rule where the implemented policy is the most voted proposal. ${ }^{18}$ T1 instead implements a PR rule where the implemented policy is the average of all proposed policies, weighted by the number of votes they received. For the example of Table 2, the implemented policy under PR is hence $(1 \times 3.5+5 \times 2.5+6 \times 5) / 11=$ 4.18, and 6 under plurality. ${ }^{19}$

The payoff structure across both treatments is the following: all participants receive a policy payoff that depends on the distance between their ideal and implemented policy, so that their policy payoff equals $12 \times[10-($ distance $)]$. For example, if the participant's ideal policy is 0 and the implemented policy is 5 , she receives $12 \times[10-5]=60$ points. Participants entering the election pay a cost of 2 points, and receive an office payoff depending on the treatment and the number of votes that their platform gets. Under plurality, the participant whose proposal is implemented gets 11 points. Under PR, the number of points equals the number of votes received by the proposal. The payoff structure here replicates the lexicographic preferences of our model in a natural and easy way to introduce in the lab. In short, lexicographic preferences are effectively introduced since the minimum effect that a change in a participant's strategy can have on her policy payoff is always greater than the effect this change can have on her office payoff. ${ }^{20}$

understanding of the rules, we decided to frame the game as a simulation of a dinner organization among friends. Of course, the structure of incentives closely follows the theoretical model of candidate entry in elections presented above. In more detail, the subjects were playing the role of candidates by first choosing whether they wanted to declare themselves as hosts of the dinner (at a cost). Potential hosts then had to propose how many food portions should be prepared for dinner. Those could be any integer number between 0 and 10. Voting was computerized (as in Table 2) and chosen policies and payoffs were implemented as described in the main text. The main reason we took this framing decision is that our experiment -in particular the implemented policy under $\mathrm{PR}$ - is quite challenging to implement in the lab, especially in a completely neutral framework. The proposed setting instead, proved understandable to subjects and it should not have created as strong framing concerns as a "left-right" spectrum.

${ }^{18}$ In case of tie, the computer decides upon the implemented policy by choosing the less extreme among the tied platforms, that is the one that is the closest to 5 . In case the tied platforms are equally extreme, the computer randomly chooses the implemented policy among them.

${ }^{19}$ We round the final value so that it equals the closest discrete point, 4 in this example.

${ }^{20}$ In some more detail, the above payoff structure together with the rounding in the PR treatment 
Treatments T1 and T2 closely replicate our theoretical setting where the three mechanisms presented in Hypotheses 1 to 3 are at play. Clearly, T1 and T2 serve as the test-bed for Hypothesis 2 on the effect of the electoral rule on the number of competing parties via participants' first stage decisions. Nevertheless, testing Hypotheses 1 and 3 using data generated by $\mathrm{T} 1$ and $\mathrm{T} 2$ is not immune to reasonable criticisms. First, our theory predicts that entry is lower in T2 than T1. Hence, our data obtained in T1 and T2 for a given number of entries will be unbalanced across electoral rules. Second, actions in the second stage with two entrants may be confounded by what happened in the entry stage. That is, subjects may self-select into two or three-party elections and therefore subjects in groups with two entrants might be different (in observable or unobservable characteristics) from those in groups with three entrants. For the above reasons, T3T6 are implementing simplified one-stage versions of T1-T2 where we eliminate the entry stage. By fixing the number of entries, we obtain further (balanced) data and robust tests of Hypotheses 1 and 3. As Table 1 summarizes, T3 and T4 involve three participants (P0,P5, and P10) and variation in the rule. T5 and T6 instead involve two participants (P0 and P10) and again variation in the rule. Hypothesis 1 can then be tested comparing data across T3 and T4 for the three entrant case, and across T5 and T6 for the two entrant case. Hypothesis 3 instead can be tested comparing data across T3 and T5 for the PR rule, and across T4 and T6 for the plurality rule.

For all treatments, at the beginning of each session, participants receive detailed instructions explaining the rules of the game, and respond to a quiz about these instructions. There is no incentive associated to this quiz, but it serves at increasing participants' understanding of the rules. The participants have all and common information about the rules and there is no deception. The instructions and quiz questions can be found in supplementary material S1 and S2. After each election, the participants see the full result of the election: the platform proposed by other participants of their group, their votes, and their payoff (full information). A screen shot of the feedback given to participants can be found in supplementary material S3, together with screen shots from decision screens (first and second stage for the T1 \& T2 treatments). Finally, at the end of each session, one election is randomly selected by the computer, and the payoffs are converted into money so that 10 points $=£ 0.7$. There is also a fixed fee of $£ 5$ for participating in the experiment. The experimental sessions lasted on average slightly less than an hour and participants made on average $£ 10.19$.

to the closest integer (see Footnote 19), and the tie breaking rule in case of the plurality treatment (see Footnote 18) jointly guarantee the lexicographic payoff structure. The tie breaking and rounding rules simply guarantee that the minimum change in policy that a change in a player's strategy can induce is of one unit. The payoff formula guarantees that the points from such minimum unitary change in policy (12 points) are always larger than the maximum payoff change from the office payoff (11 points in the plurality treatment). 
Before proceeding with our experimental results, let us describe further the link between our theoretical and experimental settings. T1 and T2 maintain the timing and preferences of our theoretical model. In the equilibrium of the proportional treatment, the parameters are chosen such that in the first stage all three subjects should enter. In the plurality treatment instead, only P0 and P10 should enter. The second stage equilibrium platforms for our experimental setup are as follows: In the plurality treatment, both $\mathrm{P} 0$ and P10 propose platform 5. In the PR treatment, the equilibrium is in mixed strategies. $^{21} \mathrm{P} 0$ assigns most weight to 2 (weight equal to $7 / 8$ ). Proposals 0 and 3 also belong in the support of the mixed strategy with weight $1 / 24$ and $1 / 12$ respectively. P10 is playing symmetrically assigning positive weights at platforms 7, 8, and 10. In expectation, the platforms proposed by $\mathrm{P} 0$ and $\mathrm{P} 10$ are 2 and 8 . P5 instead proposes 5. Regarding the treatments without entry (T3-T6), the equilibrium platforms of T3 (3-party PR) and T6 (2-party plurality) naturally coincide with the equilibrium platforms of T1 (endogenous $\mathrm{PR}$ ) and T2 (endogenous plurality). In treatment T4 (3-party plurality), the equilibrium platforms are $(4,5,6)$ for P0, P5, and P10 respectively. In treatment T5 (2-party PR), P0 and P10 play the same mixed strategies as in T1.

Summing up, despite introducing a discrete policy space in the lab for practical reasons (i.e., to implement lexicographic preferences but also obtain less noisy data than a continuum), the qualitative features presented in our three theoretically derived hypotheses are maintained. Results on the three hypotheses are presented next.

\section{Experimental results}

Table 3 presents descriptive statistics at the election level on the number of entering candidates (relevant in treatments T1 \& T2), and the average policy platform proposals (relevant in all treatments). Focusing on the endogenous entry treatments (T1 \& T2), in most elections there are three entries $(79.47 \%$ and $57.84 \%$ of the observations respectively). However, there is a substantial percentage of elections with two entering parties under both systems (18.67\% and $37.3 \%)$. In line with our theoretical prediction, descriptive statistics indicate that entry is higher in the PR treatment compared to the plurality one. There are also few elections with less than two entries (less than 5\%). From the lower panel of Table 3, we observe that the average policy platform proposal is around 5 across all treatments. Obviously, averages may hide relevant differences in distributions. Figure 3 offers the histograms of platform proposals across the six treatments.

The left panel of Figure 3 summarizes proposals obtained in the second stage of the treatments with entry (T1 \& T2). The middle panel summarizes proposals when the

\footnotetext{
${ }^{21}$ Mixed equilibria under PR were computed using Gambit (McKelvey et al. 2006).
} 
Table 3: Descriptive statistics (elections)

\begin{tabular}{lllllll}
\hline & T1 & T2 & T3 & T4 & T5 & T6 \\
& Endog. & Endog. & 3 parties & 3 parties & 2 parties & 2 parties \\
& PR & Plurality & PR & Plurality & PR & Plurality \\
\hline Number of entering parties & (Frequencies) & & & \\
\hline 0 entry & 0.00 & 0.54 & 0.00 & 0.00 & 0.00 & 0.00 \\
& $(0)$ & $(2)$ & $(0)$ & $(0)$ & $(0)$ & $(0)$ \\
1 entry & 1.87 & 4.32 & 0.00 & 0.00 & 0.00 & 0.00 \\
& $(7)$ & $(16)$ & $(0)$ & $(0)$ & $(0)$ & $(0)$ \\
2 entries & 18.67 & 37.30 & 0.00 & 0.00 & 100.00 & 100.00 \\
3 entries & $(70)$ & $(138)$ & $(0)$ & $(0)$ & $(250)$ & $(250)$ \\
& 79.47 & 57.84 & 100.00 & 100.00 & 0.00 & 0.00 \\
Average proposal & $(298)$ & $(214)$ & $(250)$ & $(250)$ & $(0)$ & $(0)$ \\
& 5.08 & 5.10 & 5.14 & 5.12 & 4.84 & 5.23 \\
& $(0.92)$ & $(0.82)$ & $(1.04)$ & $(0.97)$ & $(1.56)$ & $(1.32)$ \\
\hline
\end{tabular}

Note: Upper panel: entries are percentages, number of observations is in parentheses.

Lower panel: entries are averages, standard deviations are in parentheses.

number of competing parties is fixed to three ( $\mathrm{T} 3 \& \mathrm{~T} 4$ ), and the panel on the right when the number of competing parties is fixed to two (T5 \& T6). Solid lines represent treatments under a PR rule, dashed lines represent treatments under the plurality rule. Visual observation of those graphs suggests that platform proposals vary across treatments, where both rules and the number of competing parties seem to matter.

Focus first, on the two-party treatments (T5 \& T6). Under plurality, platforms are concentrated around the median. Under PR, platforms are more spread and towards more extreme proposals. Focusing on the three-party treatments (T3 \& T4), the message is similar. While there is a peak at the median for both rules (due to the presence of P5), subjects seem to move towards the extremes more under the PR rule than under the plurality rule. These descriptive differences in platform proposals are actually compatible with our Hypotheses that we later test. Fixing the number of parties, polarization is higher under PR than under plurality. Moreover, note that on the left graph of Figure 3, observations are obtained in treatments with endogenous entry choices, and hence proposals reflect a mixture of two and three-party elections. As one can observe, proposed platforms in the endogenous plurality treatment (T2) resemble the two-party plurality treatment (T6), while the endogenous PR treatment (T1) resembles the three-party PR treatment (T3). This observation seems in line with our theoretical prediction suggesting two entrants (P0 and P10) under the plurality treatment (T2), and three entrants (P0, $\mathrm{P} 5$, and P10) under the PR treatment (T1).

Having presented our aggregate data and descriptive differences across treatments, we 

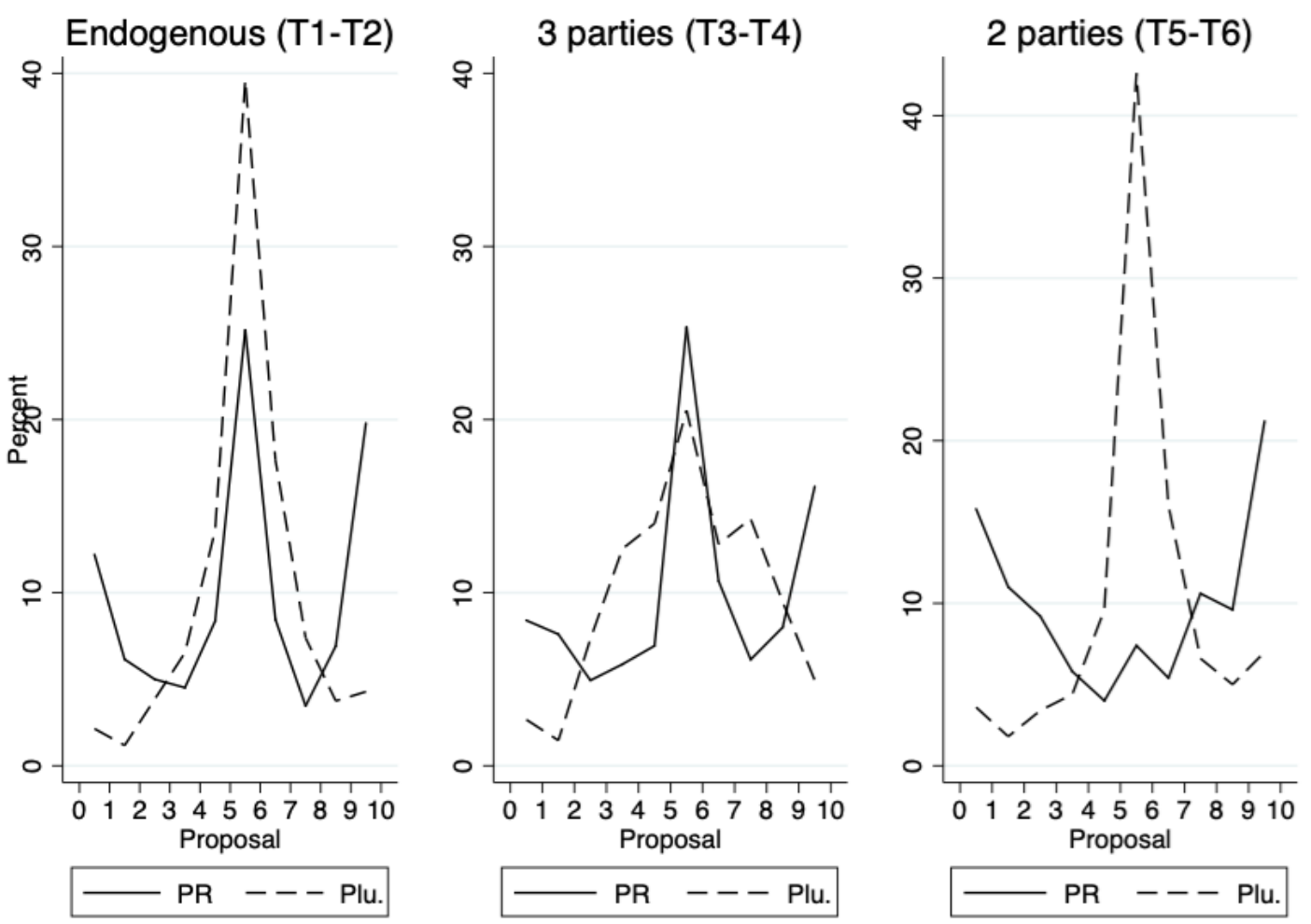

Figure 3: Histograms of proposals by treatment

proceed by formally testing our three hypotheses. First, we focus on the treatments with entry where as previously described all three effects of the electoral rule on the number of parties and polarization are present. Then we focus on treatments T3-T6 where by shutting down the entry channel we offer a clean test of Hypotheses 1 and 3.

\section{Treatments with Entry (T1-T2)}

According to Hypothesis 1, polarization should be smaller under plurality than under PR for a given number of parties. The corresponding rows of Table 4 show the average polarization, i.e. the difference between the minimal and maximal platforms on the 0-10 policy scale, per electoral system depending on whether two or three candidates entered the election. ${ }^{22}$ We observe that, in line with our model, polarization is substantially greater under PR than under plurality both in two party and three party elections. A t-test reveals that differences are statistically significant at a level of $p<0.01$.

According to Hypothesis 2, the number of entries should be larger under PR than

\footnotetext{
${ }^{22}$ While polarization is the main variable of interest in our analysis one can show that other measures of dispersion such as platforms' extremism (i.e., average distance of two most extreme platforms from the centre) behave in a similar manner.
} 
Table 4: Bivariate test of hypotheses (T1 \& T2)

\begin{tabular}{llll}
\hline Hypothesis 1 & Plurality & PR & P-value \\
\hline Polarization (2 entries) & $1.95(1.76)$ & $4.54(2.92)$ & 0.00 \\
Polarization (3 entries) & $3.17(2.04)$ & $6.95(2.24)$ & 0.00 \\
\hline Hypothesis 2 & Plurality & PR & P-value \\
\hline Number of entries & $2.52(0.61)$ & $2.78(0.46)$ & 0.00 \\
Number of entries (w/o 0,1 entries) & $2.61(0.49)$ & $2.81(0.39)$ & 0.00 \\
\hline Hypothesis 3 & 2 entries & 3 entries & P-value \\
\hline Polarization (Plurality) & $1.95(1.76)$ & $3.17(2.04)$ & 0.00 \\
Polarization (PR) & $4.54(2.92)$ & $6.95(2.24)$ & 0.00 \\
\hline
\end{tabular}

Note: Entries are averages, standard deviations are in parentheses. P-values are for two-tailed mean differences t-tests with unequal variance.

under plurality. This is exactly what we find in our data. Table 4 reveals that there are on average 2.78 entries in an election under PR, and 2.52 in an election under plurality. This difference $(+0.26)$ is equivalent to a 0.5 increase in the standard deviation of the variable across treatments (0.56), and statistically significant at a level of $p<0.01$. The results are similar when we remove the few elections with one entry or less.

Finally, according to Hypothesis 3, fixing the electoral rule, polarization is generically larger when there are three instead of two entries (the elections with zero or one entry are naturally excluded from this test). From Table 4, we see that polarization is larger by 1.22 under plurality, and by 2.41 under PR. These differences, respectively, correspond to 0.4 and 0.8 of the standard deviation of the variable across treatment and are statistically significant at a level of $p<0.01$.

Nevertheless, polarization is predicted to be strictly increasing in the number of parties only under the plurality rule. Under the PR rule, P0 and P10 face no additional incentives to approach the center when they are the sole two entrants (see Figure $2 \mathrm{~b}$ for $n=1)$. The discrepancy between our theoretical predictions and our experimental data seems to be due to our data obtained in two-party elections also containing (off equilibrium) observations where one of the two entrants is P5. In order to obtain a cleaner understanding of Hypothesis 3, in Table 5, we split two-entry elections to those that one of the two entrants is the centrist candidate P5, and those that the two entrants are P0 and $\mathrm{P} 10 .{ }^{23}$

Focusing on PR, if the two entrants are P0 and P10, Table 5 shows that polarization is not affected by the number of entrants in a significant manner (7.08 and 6.95 for two and three entries respectively). If instead the centrist candidate P5 is one of the two

\footnotetext{
${ }^{23}$ In the Appendix we also present our main bivariate tests distinguishing between the first and last elections of each experimental session (Tables A1-A3). Our main results appear robust across periods.
} 
entrants, polarization is increasing in the number entries (3.22 and 6.95 for two and three entries respectively). These results are in line with the theory. As previously detailed, when all three subjects enter in the election, polarization is in expectation equal to 6 (equilibrium PR platforms played by the two extreme candidates are in expectation 2 and 8). The same level of polarization is expected when P0 and P10 are the only two entering candidates. ${ }^{24}$ If instead, the centrist candidate P5 is one of the two entrants, polarization is in expectation equal to 5 and hence lower than when all three subjects enter. $^{25}$ Focusing on the plurality rule, Table 5 reveals that as expected, polarization is increasing in the number of parties regardless of the ideologies of the two entering candidates. ${ }^{26}$

Table 5: Breakdown of Hypothesis 3 (T1 \& T2)

\begin{tabular}{llll}
\hline & 2 entries with P5 not entering & 3 entries & P-value \\
\hline Polarization (Plurality) & $2.00(1.76)$ & $3.17(2.04)$ & 0.00 \\
Polarization (PR) & $7.08(2.60)$ & $6.95(2.24)$ & 0.80 \\
\hline & 2 entries with P5 entering & 3 entries & P-value \\
\hline Polarization (Plurality) & $1.87(1.77)$ & $3.17(2.04)$ & 0.00 \\
Polarization (PR) & $3.22(2.07)$ & $6.95(2.24)$ & 0.00 \\
\hline
\end{tabular}

Note: Entries are averages, standard deviations are in parentheses. P-values are for two-tailed mean differences t-tests with unequal variance.

Finally, we focus on individual decisions to understand which participants are responsible for the aggregate effects presented in our three hypotheses. Table 6 shows participants' decisions (entry and proposed policy platform) per electoral system as a function of their position on the 0-10 policy scale. The upper panel of the table reveals that participants with an extreme position (0 and 10) enter as often under both electoral systems (entry percentage between 0.89 and 0.94 ). However, as predicted by our model, the centrist participant enters less often under plurality than under PR (0.73 versus 0.93 , statistically significant at a level of $p<0.01)$. Hence, in line with our theory, the difference in terms of number of entries across electoral systems is due to the centrist candidate entering at a lower rate under plurality than under PR.

The lower panel of Table 6 shows that the platform proposed by the participant located

\footnotetext{
${ }^{24}$ This follows from this off equilibrium subgame being identical to T5 and the previously detailed equilibrium for our two-party PR treatment.

${ }^{25}$ The equilibrium strategies of the off equilibrium subgame in which only P5 and P10 enter are as follows: P5 assigns weights equal to $7 / 8,1 / 12$, and $1 / 24$ at platforms 2,3 , and 4 respectively; while P10 assigns weights equal to $11 / 12,1 / 24$, and $1 / 24$ at platforms 7,8 , and 10 respectively. In expectation, P5's platform is 2.17 and P10's platform is 7.17 , hence leading to polarization of 5 . A symmetric situation arises when the entrants are P5 and P0.

${ }^{26}$ In a two-party plurality election, regardless of the ideology of the entrants, both propose platform 5. Recall from the described equilibrium in T4 that polarization is higher when all three subjects enter.
} 
Table 6: Individual-level decisions (T1 \& T2)

\begin{tabular}{lccc}
\hline Entry & Plurality & PR & P-value \\
\hline P0 & $0.89(0.31)$ & $0.91(0.29)$ & 0.50 \\
P5 & $0.73(0.45)$ & $0.93(0.25)$ & 0.00 \\
P10 & $0.90(0.30)$ & $0.94(0.25)$ & 0.10 \\
\hline Proposed platform & Plurality & PR & P-value \\
\hline P0 & $3.84(1.69)$ & $1.80(2.06)$ & 0.00 \\
P5 & $5.09(0.72)$ & $5.01(0.77)$ & 0.19 \\
P10 & $6.37(1.63)$ & $8.45(1.80)$ & 0.00 \\
\hline
\end{tabular}

Note: Entries are averages, standard deviations are in parentheses. P-values are for two-tailed mean differences t-tests with unequal variance.

at the policy position 5 is no different under both electoral systems and actually close to our theoretical prediction for the case of three party elections for both rules (between 5.01 to 5.09 on average). However, the participants located at positions 0 and 10 choose more extreme platforms under PR than under plurality. The average platform chosen is, respectively, 1.80 and 8.45 under PR, and 3.84 and 6.37 under plurality. The standard deviation also indicates that there is more variation in the platform chosen by participants located at 0 and 10, than in the platform chosen by the participant located at 5 . The extreme candidates hence seem responsible for the observed difference in polarization across electoral systems.

\section{Treatments without Entry (T3-T6)}

We next present data obtained in treatments T3-T6 where the number of candidates is fixed. These results offer a clean test of Hypotheses 1 and 3. In contrast to T1 and T2, we now also control the number of entrants and their ideologies, while we avoid any confounding concerns due to the entry stage. Also our number of observations is large and our data is balanced. Results are in line with our theoretical predictions, and provide robust support of the results obtained in the treatments with entry T1 and T2.

Table 7 reports the results of bivariate tests of the relevant hypotheses. These results corroborate the findings presented above: In line with Hypothesis 1, polarization is larger under PR than under plurality when there are two (+3.92 points) as well as three competing candidates $(+1.94$ points $)$. These differences are statistically significant at a level of $p<0.01$. In line with Hypothesis 3, we also observe that polarization is larger when there are three rather than two parties under plurality (the increase is of +2.32 $(p<0.01))$. Under PR, the number of parties does not substantively affect the degree of polarization $(+0.34$, not statistically significant). Finally, in Table 8 , we summarize individual platforms across treatments and participants' ideal policies. Similar to Table 
Table 7: Bivariate test of hypotheses (T3-T6)

\begin{tabular}{llll}
\hline Hypothesis 1 & Plurality & PR & P-value \\
\hline Polarization (2 entries) & $2.14(2.19)$ & $5.73(2.72)$ & 0.00 \\
Polarization (3 entries) & $4.13(1.95)$ & $6.07(2.33)$ & 0.00 \\
\hline Hypothesis 3 & 2 entries & 3 entries & P-value \\
\hline Polarization (Plurality) & $2.14(2.19)$ & $4.13(1.95)$ & 0.00 \\
Polarization (PR) & $5.73(2.72)$ & $6.07(2.33)$ & 0.13 \\
\hline
\end{tabular}

Note: Entries are averages, standard deviations are in parentheses. P-values are for two-tailed mean differences t-tests with unequal variance.

6, extreme participants are the ones responsible for changes in polarization levels across electoral systems.

Table 8: Individual-level decisions (T3-T6)

\begin{tabular}{lccc}
\hline Proposed platform (2 entries) & Plurality & PR & P-value \\
\hline P0 & $4.30(1.98)$ & $2.12(2.37)$ & 0.00 \\
P10 & $6.16(1.65)$ & $7.56(2.14)$ & 0.00 \\
\hline Proposed platform (3 entries) & Plurality & PR & P-value \\
\hline P0 & $3.70(2.11)$ & $2.34(2.22)$ & 0.00 \\
P5 & $5.01(1.53)$ & $5.12(1.13)$ & 0.35 \\
P10 & $6.64(1.79)$ & $7.96(1.83)$ & 0.00 \\
\hline
\end{tabular}

Note: Entries are averages, standard deviations are in parentheses. P-values are for two-tailed mean differences t-tests with unequal variance.

We can summarize our experimental results as following. In line with Hypothesis 1 [first-order effect], we observe that, PR increases the distance between the platform chosen by two most extreme candidates compared to plurality, regardless of the number of entering candidates. In line with Hypothesis 2 [second-order effect], we observe that PR increases the number of entering candidates because of the centrist candidate entering at a lower rate under plurality. Finally, we observe that, in line with Hypothesis 3 [thirdorder effect], polarization is increasing in the number of entries because of the non-centrist candidates choosing more extreme platforms when the centrist candidate enters.

\section{Conclusions}

Our paper develops a formal model where both candidates' entry and location decisions are endogenously determined under different electoral rules. This allows us to account for the bi-directional effect between party platform positions (polarization) and entry decisions in addition to the first-order effect of electoral rule (dis)proportionality on po- 
larization. Thus our model provides a formal result in line with Duverger (1954) hypotheses that stipulate that more candidates advancing distinct positions participate in proportional elections than in majoritarian ones.

But, perhaps more importantly, our model identifies three distinct channels that are simultaneously in operation and generates testable empirical predictions. We then take our model in the lab, where we find strong support for our generated predictions: even controlling for the number of competing candidates, disproportional elections induce lower levels of polarization (what we call the first-order effect); but, in addition to this effect, disproportional rules (by providing centripetal incentives and inducing over-competition in the center of the policy space) affect entry decisions in a negative way (second-order effect). Thus, a third-order effect of electoral rules on polarization operates via the number of candidates: even for the same degree of electoral rule disproportionality, the reduction in the number of candidates has a negative effect on polarization.

By identifying those three channels and showing their simultaneous existence in the lab, our paper sheds more light in the relationship between electoral rules, strategic entry and polarization. It highlights the fact that strategic decisions on location and entry that parties make are intrinsically intertwined and are both affected by type of electoral institutions via the incentives they provide. Thus to understand the impact of institutional choice on the fundamentals of electoral competition we require a more nuanced approach that does not mute such channels. 


\section{Appendix}

Proof of Proposition 1. Given the available actions for each party in the first stage there are eight policy-selection subgames. To fully characterize an equilibrium for the whole game we first need to see what happens in each of these subgames.

Case 1 (No party enters) In this case we have assumed that a status quo policy $q \in[0,1]$ is implemented (known to everybody).

Case 2 (A single party enters) If only party $j$ entered then it selects $p_{j}=\pi_{j}$ as it is the unique choice that maximizes $U_{j}(\hat{p})$ (given that $\hat{p}=p_{j}$ in this case). So if only $L$ entered the race we have $\hat{p}=p_{L}=\pi_{L}=0$, if only $C$ entered the race we have $\hat{p}=$ $p_{C}=\pi_{C}=\frac{1}{2}$ and if only $R$ entered the race we have $\hat{p}=p_{R}=\pi_{R}=1$.

Case 3 (Two parties enter) If only party $j$ and party $k$ such that $\pi_{j}<\pi_{k}$ entered then they select $\left(p_{j}, p_{k}\right)=\left(\frac{1}{2}-\frac{1}{2 n}, \frac{1}{2}+\frac{1}{2 n}\right)$ and $\hat{p}=\frac{1}{2}$. This is trivial for the case $(j, k)=(L, R)$ (from Proposition 1 of Matakos et al. (2016)) but it directly extends to the cases $(j, k)=(L, C)$ and $(j, k)=(C, R)$ as well. To see why it does, consider for example that only parties $L$ and $C$ entered the race. From Proposition 1 and 2 of Matakos et al. (2016) we know that if parties $L$ and $R$ compete there exists a unique equilibrium and in this unique equilibrium $\hat{p}=\frac{1}{2}$. Since in that case each party wishes to drag the implemented policy as near as possible to a different extreme policy it follows that, for party $L$, the strategy $\frac{1}{2}-\frac{1}{2 n}$ guarantees that $\hat{p} \leq \frac{1}{2}$ independently of what $R$ chooses and, for party $R$, the strategy $\frac{1}{2}+\frac{1}{2 n}$ guarantees that $\hat{p} \geq \frac{1}{2}$ independently of what $L$ chooses. Moreover, uniqueness implies that when $p_{L}=\frac{1}{2}-\frac{1}{2 n}\left(p_{R}=\left(\frac{1}{2}+\frac{1}{2 n}\right)\right.$ we have that $\hat{p}<\frac{1}{2}$ $\left(\hat{p}>\frac{1}{2}\right)$ for any $p_{R} \neq \frac{1}{2}+\frac{1}{2 n}\left(p_{L} \neq \frac{1}{2}-\frac{1}{2 n}\right)$. Returning in our extended form game and in the case in which only parties $L$ and $C$ entered the race we notice with the help of the above that a) $\left(p_{L}, p_{C}\right)=\left(\frac{1}{2}-\frac{1}{2 n}, \frac{1}{2}+\frac{1}{2 n}\right)$ with $\hat{p}=\frac{1}{2}$ must be an equilibrium because if $L$ deviates to another policy we will get $\hat{p}>\frac{1}{2}$ (party $L$ will be strictly worse off) and if party $C$ deviates to any other policy we will get $\hat{p}<\frac{1}{2}$ (party $C$ will be strictly worse off), and b) this equilibrium is unique. This is so because for any $p_{L}$ the best response of $C$ is $p_{C}=1-p_{L}$ (so as to induce $\hat{p}=\frac{1}{2}$ ) while for any $p_{C} \neq \frac{1}{2}+\frac{1}{2 n}$ party $L$ 's best response induces $\hat{p}<\frac{1}{2}$. All these obviously hold (in the reverse way) for the $(j, k)=(C, R)$ case as well.

Case 4 (All three parties enter) If all three parties enter then we are in the case of Proposition 3 of Matakos et al. (2016) and $\left(p_{L}, p_{C}, p_{R}\right)=\left(\frac{1}{2}-\frac{1}{n+1}, \frac{1}{2}, \frac{1}{2}+\frac{1}{n+1}\right)$ and $\hat{p}=\frac{1}{2}$.

So each policy selection subgame has essentially a unique equilibrium. This makes identification of a subgame perfect equilibrium (SPE) tractable.

First, we argue that in a SPE at least two parties should enter. If no party is expected 
to enter then the implemented policy will be $q \in[0,1]$. In that case a party $j$ with $\pi_{j} \neq q$ is strictly better off by entering and, thus, implementing her ideal policy. If only one extreme party is expected to enter and implement its ideal policy then the other extreme party, for example, is better off by entering too and, thus, moving the implemented policy to $\frac{1}{2}$. If only the centrist party is expected to enter and implement its ideal policy $\left(\frac{1}{2}\right)$ then an extreme party has incentives to enter. By entering the extreme party will not affect the implemented policy (we argued in case 3 that if the centrist runs against an extremist then the implemented policy will be $\frac{1}{2}$ ) but will enjoy an increase in the second element of its lexicographic preferences, $\psi_{j}$. This is so because if the extremist $j$ does not enter and only the centrist party runs, then $\psi_{j}=0$ (because $S_{j}=0$ and $c=0$ ) but if it runs against the centrist it will enjoy $\psi_{j}=0$ (because $S_{j}=\frac{1}{2}$ and $c<\frac{1}{2}$ ).

Second, we will argue that if a SPE in which all three parties enter exists then generically no SPE exists in which only two parties enter. This is straightforward for the following reason. If a SPE in which all three parties enter exists then this implies that if a party expects that only the two other parties will run it also strictly prefers to run (apart from cases of measure zero in which for some party/ies $S_{j}=\hat{c}$ in the equilibrium of the three party subgame); entering does not affect implemented policy but increases the value of $\psi_{j}$.

Third, we notice that in the equilibrium of the three party subgame $\frac{\partial S_{C}}{\partial n}<0$. This implies that in the equilibrium of the three party subgame $\frac{\partial S_{L}}{\partial n}=\frac{\partial S_{R}}{\partial n}>0$.

By a careful composition of all the observations above we arrive to the main result. When $n=1$ we know that in the equilibrium of the three party subgame $S_{L}=S_{R}=\frac{1}{4}$ and $S_{C}=\frac{1}{2}$. Since $\hat{c}<\frac{1}{4}$ it follows that for $n=1$ all three parties entering and selecting $\left(p_{L}^{* * *}, p_{C}^{* * *}, p_{R}^{* * *}\right)=\left(\frac{1}{2}-\frac{1}{n+1}, \frac{1}{2}, \frac{1}{2}+\frac{1}{n+1}\right)$ is the a SPE of the game. This is so because if a party $j$ deviated to not entering it would not affect the implemented policy but it would get a strictly lower $\psi_{j}$. Moreover, by our first and second argument it becomes evident that this SPE is unique. By increasing $n$ our third observation dictates that the SPE in which all three parties enter is still the unique one as long as $S_{C}>\hat{c}$. Since $\frac{\partial S_{C}}{\partial n}<0$ and for $n \rightarrow \infty$ we have that $S_{C} \rightarrow 0$ there should exist some $\hat{n}>0$ such that for every $n \leq \hat{n}$ we have $S_{C} \geq \hat{c}$ and for every $n>\hat{n}$ we have $S_{C}<\hat{c}$. For $n \leq \hat{n}$ as stated above we have a unique SPE and in this equilibrium all three parties enter. For $n>\hat{n}$ the unique SPE is such that only parties $L$ and $R$ enter and their platform choices are $\left(p_{L}^{* *}, p_{R}^{* *}\right)=\left(\frac{1}{2}-\frac{1}{2 n}, \frac{1}{2}+\frac{1}{2 n}\right)$. Existence is established by the following argument. If only parties $L$ and $R$ are expected to run then $C$ is strictly better off by not running. Its decision to enter does not affect the implemented policy but if it does not run it gets $\psi_{C}=0$ while if it runs it gets $\psi_{C}<0$. Party $L(R)$ is strictly better off by running because if it does not the other extremist party will run alone and will thus implement its 
ideal policy, while if it runs the implemented policy will be $\frac{1}{2}$. Uniqueness is guaranteed by the facts that a) an equilibrium with three parties entering is not feasible (as party $C$ is strictly better off by staying out when the other two are expected to run) and b) if another SPE exists it should be such that only parties $L$ and $C$ ( $R$ and $C$ ) run. If party $R$ expects that parties $L$ and $C$ will run then it is strictly better off by running. Its entry decision will not affect the implemented policy but it will increase its $\psi_{R}$ from zero (in the case of no entry) to something strictly positive (in the case of entry). This is so because in the equilibrium of the three party subgame a) $\psi_{R}>0$ for $n=1$ and b) $\frac{\partial \psi_{R}}{\partial n}=\frac{\partial S_{R}}{\partial n}>0$.

\section{Additional Tables}

Table A1: Bivariate test of hypotheses by period (T1 \& T2)

\begin{tabular}{llll}
\hline \multicolumn{4}{c}{ 15 first elections } \\
\hline Hypothesis 1 & Plurality & PR & P-value \\
\hline Polarization (2 entries) & $2.00(1.84)$ & $4.27(3.11)$ & 0.00 \\
Polarization (3 entries) & $3.34(2.26)$ & $6.54(2.32)$ & 0.00 \\
\hline Hypothesis 2 & Plurality & PR & P-value \\
\hline Number of entries & $2.46(0.64)$ & $2.76(0.48)$ & 0.00 \\
Number of entries (w/o 0,1 entries) & $2.57(0.50)$ & $2.80(0.40)$ & 0.00 \\
\hline Hypothesis 3 & 2 entries & 3 entries & P-value \\
\hline Polarization (Plurality) & $2.00(1.84)$ & $3.34(2.26)$ & 0.00 \\
Polarization (PR) & $4.27(3.11)$ & $6.54(2.32)$ & 0.00 \\
\hline & & & \\
\hline & 10 last elections & & \\
\hline Hypothesis 1 & Plurality & PR & P-value \\
\hline Polarization (2 entries) & $1.85(1.61)$ & $5.04(2.52)$ & 0.00 \\
Polarization (3 entries) & $2.95(1.70)$ & $7.52(2.00)$ & 0.00 \\
\hline Hypothesis 2 & Plurality & PR & P-value \\
\hline Number of entries & $2.63(0.53)$ & $2.81(0.43)$ & 0.00 \\
Number of entries (w/o 0,1 entries) & $2.66(0.47)$ & $2.83(0.38)$ & 0.00 \\
\hline Hypothesis 3 & 2 entries & 3 entries & P-value \\
\hline Polarization (Plurality) & $1.85(1.61)$ & $2.95(1.70)$ & 0.00 \\
Polarization (PR) & $5.04(2.52)$ & $7.52(2.00)$ & 0.00 \\
\hline
\end{tabular}

Note: Entries are averages, standard deviations are in parentheses. P-values are for two-tailed mean differences t-tests with unequal variance. 
Table A2: Bivariate test of hypotheses, breakdown of Hypothesis 3 by period (T1-T2)

\begin{tabular}{|c|c|c|c|}
\hline \multicolumn{4}{|c|}{15 first elections } \\
\hline & 2 entries with P5 not entering & 3 entries & P-value \\
\hline Polarization (Plurality) & $2.12(1.93)$ & $3.34(2.26)$ & 0.00 \\
\hline \multirow[t]{2}{*}{ Polarization (PR) } & $7.00(2.83)$ & $6.54(2.32)$ & 0.55 \\
\hline & 2 entries with P5 entering & 3 entries & $\mathrm{P}$-value \\
\hline Polarization (Plurality) & $1.84(1.72)$ & $3.34(2.26)$ & 0.00 \\
\hline Polarization (PR) & $2.90(2.25)$ & $6.54(2.32)$ & 0.00 \\
\hline \multicolumn{4}{|c|}{10 last elections } \\
\hline & 2 entries with $\mathrm{P} 5$ not entering & 3 entries & $\mathrm{P}$-value \\
\hline Polarization (Plurality) & $1.82(1.47)$ & $2.95(1.70)$ & 0.00 \\
\hline \multirow[t]{2}{*}{ Polarization (PR) } & $7.22(2.33)$ & $7.52(2.00)$ & 0.71 \\
\hline & 2 entries with P5 entering & 3 entries & $\mathrm{P}$-value \\
\hline Polarization (Plurality) & $1.93(1.98)$ & $2.95(1.70)$ & 0.09 \\
\hline Polarization (PR) & $3.81(1.68)$ & $7.52(2.00)$ & 0.00 \\
\hline
\end{tabular}

Note: Entries are averages, standard deviations are in parentheses. P-values are for two-tailed mean differences t-tests with unequal variance.

Table A3: Bivariate test of hypotheses by period (T3-T6)

\begin{tabular}{llll}
\hline \multicolumn{4}{c}{ 15 first elections } \\
\hline Hypothesis 1 & Plurality & PR & P-value \\
\hline Polarization (2 entries) & $2.53(2.36)$ & $5.53(2.88)$ & 0.00 \\
Polarization (3 entries) & $3.93(1.92)$ & $5.76(2.52)$ & 0.00 \\
\hline Hypothesis 3 & 2 entries & 3 entries & P-value \\
\hline Polarization (Plurality) & $2.53(2.36)$ & $3.93(1.92)$ & 0.00 \\
Polarization (PR) & $5.53(2.88)$ & $5.76(2.52)$ & 0.46 \\
\hline
\end{tabular}

\begin{tabular}{llll}
\hline \multicolumn{4}{c}{ 10 last elections } \\
\hline Hypothesis 1 & Plurality & PR & P-value \\
\hline Polarization (2 entries) & $1.62(1.96)$ & $6.03(2.44)$ & 0.00 \\
Polarization (3 entries) & $4.43(1.96)$ & $6.54(1.93)$ & 0.00 \\
\hline Hypothesis 3 & 2 entries & 3 entries & P-value \\
\hline Polarization (Plurality) & $1.62(1.96)$ & $4.43(1.96)$ & 0.00 \\
Polarization (PR) & $6.03(2.44)$ & $6.54(1.93)$ & 0.10 \\
\hline
\end{tabular}

Note: Entries are averages, standard deviations are in parentheses. P-values are for two-tailed mean differences t-tests with unequal variance. 


\section{References}

Alesina, A. And H. Rosenthal (1996): "A theory of divided government," Econometrica: Journal of the Econometric Society, 64, 1311-1341.

Aragones, E. And T. R. Palfrey (2004): "The effect of candidate quality on electoral equilibrium: An experimental study," American Political Science Review, 98, 77-90.

Austen-Smith, D. And J. Banks (1988): "Elections, coalitions, and legislative outcomes," American Political Science Review, 82, 405-422.

Baron, D. P. And D. Diermeier (2001): "Elections, governments, and parliaments in proportional representation systems," Quarterly Journal of Economics, 116, 933-967.

Baron, D. P., D. Diermeier, And P. Fong (2012): "A dynamic theory of parliamentary democracy," Economic Theory, 49, 703-738.

Battaglini, M., R. B. Morton, and T. R. Palfrey (2010): "The swing voter's curse in the laboratory," Review of Economic Studies, 77, 61-89.

Besley, T. And S. Coate (1997): "An economic model of representative democracy," Quarterly Journal of Economics, 112, 85-114.

Blais, A. And A. Dobrzynska (1998): "Turnout in electoral democracies," European Journal of Political Research, 33, 239-262.

Bol, D., A. Blais, And S. Labbé St-Vincent (2018): "Which matters most: Party strategic exit or voter strategic voting?" Political Science Research and Methods, 6, $197-216$.

Bol, D., A. Dellis, AND M. OAK (2016): "Comparison of voting procedures using models of electoral competition with endogenous candidacy," in The Political Economy of Social Choices, Springer, 21-54.

Bouton, L., M. Castanheira, And A. Llorente-Saguer (2016): "Divided majority and information aggregation: Theory and experiment," Journal of Public Economics, 134, 114-128.

Cadigan, J. (2005): "The citizen candidate model: An experimental analysis," Public Choice, 123, 197-216.

Calvo, E. And T. Hellwig (2011): "Centripetal and centrifugal incentives under different electoral systems," American Journal of Political Science, 55, 27-41.

Casella, A., A. Llorente-Saguer, and T. R. Palfrey (2012): "Competitive equilibrium in markets for votes," Journal of Political Economy, 120, 593-658.

Cox, G. W. (1990): "Centripetal and centrifugal incentives in electoral systems," American Journal of Political Science, 34, 903-935. 
De Sinopoli, F. And G. Iannantuoni (2007): "A spatial voting model where proportional rule leads to two-party equilibria," International Journal of Game Theory, $35,267-286$.

(2008): "Extreme voting under proportional representation: the multidimensional case," Social Choice and Welfare, 30, 401-417.

Dellis, A. (2013): "The two-party system under alternative voting procedures," Social Choice and Welfare, 40, 263-284.

Dellis, A. AND M. OAK (2016): "Multiple votes, multiple candidacies and polarization," Social Choice and Welfare, 46, 1-38.

Duverger, M. (1954): Political parties: Their organization and activity in the modern state, Methuen.

Elbittar, A. And A. Gomberg (2009): "An experimental study of the citizencandidate model," in Political Economy of Democracy. Enriquetta Aragonès, Carmen Beviá, Humberto Lllavador and Norman Schofield (eds.) Fundación BBVA Conference Proceedings.

Feddersen, T. J., I. Sened, and S. G. Wright (1990): "Rational voting and candidate entry under plurality rule," American Journal of Political Science, 34, 10051016.

FEY, M. (1997): "Stability and coordination in Duverger's law: A formal model of preelection polls and strategic voting," American Political Science Review, 91, 135147.

FISCHBACHER, U. (2007): "z-Tree: Zurich toolbox for ready-made economic experiments," Experimental Economics, 10, 171-178.

Gerber, A. And I. Ortuño-Ortín (1998): "Political compromise and endogenous formation of coalitions," Social Choice and Welfare, 15, 445-454.

GreineR, B. (2015): "Subject pool recruitment procedures: organizing experiments with ORSEE," Journal of the Economic Science Association, 1, 114-125.

Grofman, B. (2008): "The Impact of Electoral Laws on Political Parties," in The Impact of Electoral Laws on Political Parties, ed. by D. A. Wittman and B. R. Weingast, Oxford University Press.

Grosser, J. And T. R. Palfrey (2019): "Candidate entry and political polarization: An experimental study," American Political Science Review, 113, 209-225.

Hamlin, A. And M. Huortlund (2000): "Proportional representation with citizen candidate," Public Choice, 1033, 205?-230.

Herrera, H., A. Llorente-Saguer, and J. C. McMurray (2019a): "Information aggregation and turnout in proportional representation: A laboratory experiment," Journal of Public Economics (forthcoming). 
(2019b): "The marginal voter's curse," Economic Journal (forthcoming).

Herrera, H., M. Morelli, And S. Nunnari (2016): "Turnout across democracies," American Journal of Political Science, 60, 607-624.

Herrera, H., M. Morelli, and T. R. Palfrey (2014): "Turnout and power sharing," Economic Journal, 124, F131-F162.

Huck, S., Müller, And N. J. VRIend (2002): "The east End, the West End and King's Cross: On Clustering in the Four-Player Hotelling Game," Economic Inquiry, 40, 231-240.

IARYCZOWER, M. AND A. MAtTozzi (2013): "On the nature of competition in alternative electoral systems," Journal of Politics, 71, 829-853.

Kamm, A. (2017): "Plurality Voting versus Proportional Representation in the CitizenCandidate Model: An Experiment," University of Amsterdam, Mimeo.

LEVY, G. (2004): "A model of political parties," Journal of Economic Theory, 115, $250-277$.

LiJPhart, A. (1984): Democracies: Patterns of majoritarian and consensus government in twenty-one countries, Yale University Press.

- (1994): Electoral systems and party systems: A study of twenty-seven democracies, 1945-1990, vol. 18, Oxford University Press.

Lizzeri, A. AND N. Persico (2001): "The provision of public goods under alternative electoral incentives," American Economic Review, 91, 225-239.

Llavador, H. (2006): "Electoral platforms, implemented policies, and abstention," Social Choice and Welfare, 27, 55-81.

Matakos, K., O. Troumpounis, and D. Xefteris (2016): "Electoral rule disproportionality and platform polarization," American Journal of Political Science, 60, 1026-1043.

McKelvey, R. D., A. M. Mclennan, And T. L. Turocy (2006): "Gambit: Software tools for game theory," .

MERRILl, S. AND J. AdAms (2007): "The effects of alternative power-sharing arrangements: Do "moderating" institutions moderate party strategies and government policy outputs?" Public Choice, 131, 413-434.

Milesi-Ferretti, G. M., R. Perotti, and M. Rostagno (2002): "Electoral systems and public spending," Quarterly Journal of Economics, 609-657.

Morelli, M. (2004): "Party formation and policy outcomes under different electoral systems," Review of Economic Studies, 71, 829-853.

OrTuÑo-Ortín, I. (1997): "A spatial model of political competition and proportional representation," Social Choice and Welfare, 14, 427-438. 
Osborne, M. J. (1993): "Candidate positioning and entry in a political competition," Games and Economic Behavior, 5, 133-151.

Osborne, M. J. And A. Slivinski (1996): "A Model of Political Competition with Citizen-Candidates," Quarterly Journal of Economics, 111, 65-96.

Palfrey, T. (1984): "Spatial equilibrium with entry," Review of Economic Studies, 51, $139-156$.

Palfrey, T. R. (2009): "Laboratory Experiments in Political Economy," Annual Review of Political Science, 12, 379-388.

Persson, T., G. Roland, and G. Tabellini (2007): "Electoral rules and government spending in parliamentary democracies," Quarterly Journal of Political Science, 2, 155188.

Persson, T., G. Tabellini, and F. Trebbi (2003): "Electoral rules and corruption," Journal of the European Economic Association, 1, 958-989.

Persson, T. And G. E. Tabellini (2002): Political economics: Explaining economic policy, MIT press. (2005): The economic effects of constitutions, MIT press.

SAPORITI, A. (2014): "Power sharing and electoral equilibrium," Economic Theory, 55, $705-729$.

TAAgeperA, R. (1986): "Reformulating the cube law for proportional representation elections," American Political Science Review, 80, 489-504.

TaAgepera, R. And M. S. Shugart (1989): Seats and votes: The effects and determinants of electoral systems, Yale University Press New Haven.

TheIL, H. (1969): "The desired political entropy," American Political Science Review, $63,521-525$.

Troumpounis, O. And D. Xefteris (2016): "Incomplete information, proportional representation and strategic voting," Social Choice and Welfare, 47, 879-903.

Tsakas, N. And D. Xefteris (2018): "Electoral Competition with Third Party Entry in the Lab," Journal of Economic Behavior and Organization, 148, 121-134.

Tsakas, N., D. Xefteris, And N. Ziros (2018): "Vote trading in power-sharing systems: A laboratory investigation," Available at SSRN.

Xefteris, D. (2016): "Stability in electoral competition: A case for multiple votes," Journal of Economic Theory, 161, 76-102. 